\title{
Correlation Between Neuron-Specific Enolase and Serum Glucose Level in Patients with Acute Ischemic Stroke
}

\author{
Hoang Hai Binh ${ }^{1}$, Nguyen Huu Son*2 and Phan Mai Quoc Thanh ${ }^{3}$ \\ ${ }^{1}$ General Internal Medicine and Geriatric Department, Hue Central Hospital, Vietnam \\ ${ }^{2}$ Pediatric Center, Hue Central Hospital, Vietnam \\ ${ }^{3}$ Stroke Department, Hue Central Hospital, Vietnam \\ *Corresponding author: Nguyen Huu Son, Pediatric Center, Hue Central Hospital. 16 Le Loi street, Hue City, Vietnam
}

\section{ARTICLE INFO}

Received: 彗 April 25, 2019

Published: May 08, 2019

Citation: Hoang Hai Binh, Nguyen Huu Son, Phan Mai Quoc Thanh. Correlation Between Neuron-Specific Enolase and Serum Glucose Level in Patients with Acute Ischemic Stroke. Biomed J Sci \& Tech Res 17(5)-2019. BJSTR. MS.ID.003064.

Keywords: Hyperglycemia; Ischemic Stroke; Neuron-Specific enolase

Abbreviations: NSE: Neuron Specific Enolase; LDL: Low-Density Lipoprotein; HDL: High-Density Lipoprotein; CAD: Coronary Artery Disease; NIHSS: National Institute of Health Stroke Scale; CNS: Central Nervous System; IS: Ischemic Stroke

\section{ABSTRACT}

Background: Stroke is defined as a sudden onset of a neurological deficit caused by an acute focal injury to the central nervous system due to a vascular cause. NSE is released into the cerebrospinal fluid and blood, in response to different forms of brain injury, including ischemic stroke, and can serve as a peripheral indicator of the ongoing neuronal damage. This present study aims to investigate the correlation between neuron-specific enolase and serum glucose level in patients with acute ischemic stroke at the time of admission.

Patients and Methods: We investigated 49 patients with complete stroke who were admitted to Critical Care Department and Stroke Department of Hue Central Hospital. NSE was measured with commercially available quantitative 'sandwich' enzyme-linked immunosorbent assay kits obtained from R and D Systems. Hyperglycemia was defined as blood glucose concentration $\geq 7 \mathrm{mmol} / \mathrm{L}$, and measured using the glucose oxidase method immediately.

Results: Significantly increased NSE levels were found in ischemic stroke patients as compared to the control. Hyperglycemic ischemic stroke patients had increased levels of NSE, and National Institute of Health stroke scale scores (NIHSS score) compared to normoglycemic ischemic stroke patients. In addition the serum NSE level of hyperglycemic stroke patients was also positively correlated with the serum glucose $(r=0.673 \mathrm{P}<0.01)$.

Conclusion: Hyperglycemia predicts an increased risk of poor outcome after ischemic stroke and it is reflected by a significantly increased level of Neuron-Specific Enolase.

\section{Introduction}

Stroke is defined as a sudden onset of a neurological deficit caused by an acute focal injury to the central nervous system due to a vascular cause [1]. The incidence of strokes occurring every year worldwide is about 17 million and it is the second leading cause of death after coronary artery disease [2]. Elevated serum glucose is common in the early phase of stroke. The prevalence of hyperglycemia, defined as blood glucose level $>6.0 \mathrm{mmol} /$ L (108 mg / dL), has been observed in two thirds of all ischemic stroke subtypes on admission, and in at least $50 \%$ in each subtype including lacunar strokes [3]. The recent experimental studies add that hyperglycemia aggravates edema formation in the zone surrounding cerebral hemorrhages [4]. Other studies have also shown that hyperglycemia in ischemic stroke is associated with poor outcome $[5,6]$, however, it remains uncertain whether hyperglycemia directly contributes to the worsening of ischemic stroke.

Neuron-specific enolase (NSE) is present in high concentrations in neurons, where it catalyses the conversion of 2-phosphoglycerate into phosphoenolpyruvate. NSE is released into the cerebrospinal fluid and blood, in response to different forms of brain injury, including ischemic stroke, and can serve as a peripheral indicator of 
the ongoing neuronal damage [7-10]. Many studies have provided strong evidence for lipids as a risk factor for coronary artery disease (CAD). These studies demonstrate a direct relationship between total cholesterol, low-density lipoprotein (LDL), and CAD, and an inverse relationship between high-density lipoprotein (HDL) and CAD $[11,12]$. These relationships are not yet clearly established for ischemic stroke and some studies even question whether cholesterol is a risk factor for stroke or not. This present study aims to investigate a difference in serum NSE concentration between stroke patients and healthy control, followed by comparing serum NSE levels and the National Institute of Health Stroke Scale (NIHSS) in patients with acute ischemic stroke, with and without increased serum glucose concentrations.

\section{Patients and Methods}

\section{Patients}

We consecutively included 49 patients, 28 men and 21 women with their first-ever ischemic stroke. They were admitted within 72 hours of the onset of stroke symptoms to the Critical Care Department and Stroke Department of Hue Central Hospita between April 2018 đến April 2019. All the patients were treated according to the guidelines of the American Heart Association and none of them underwent surgical procedures. Our exclusion criteria were
a) CNS Infection
b) Stroke of more than 72 hours
c) Peripartum stroke, and
d) Head Trauma

The study protocol was approved by the appropriate hospital Ethical Committee and informed consent was obtained from all the study participants. We also enrolled a group of 50 control individuals with no history of stroke, who had admitted to our hospital for routine checkup. Some controls were recruited from the hospital staff.

\section{Methods}

Blood samples were collected at the time of admission. The patients blood was then centrifuged, serum samples separated, aliquoted, and kept frozen at $-20^{\circ} \mathrm{C}$, prior to analysis. NSE was measured with commercially available quantitative 'sandwich' enzyme-linked immunosorbent assay kits obtained from the $\mathrm{R}$ and D Systems. Sensitivity of the assay was $1 \mu \mathrm{g} / \mathrm{L}$ for NSE.
Hyperglycemia was defined as blood glucose concentration $\geq 7 \mathrm{mmol} / \mathrm{L}$, and measured by the Glucose oxidase method, immediately. The degrees of neurological deficit during the acute phase were evaluated by National Institute of Health Stroke Scale at the time of admission.

\section{Statistical Analysis}

The statistical analysis was carried out using SPSS 20.0. The results were presented as mean \pm SD values. Each distribution was tested for normality using the Kolmogorov-Smirnov test, prior to any further analysis. Significance of age difference between the groups was tested using the parametric Student's t test. Statistical significance of the difference between the categorical variables was tested with the Chi-square test. The correlations were evaluated by using the regression analysis with the Pearson's coefficient. Only P-values $\leq 0.05$ were considered significant. Data from different groups were analyzed by the parametric Student's $t$ test.

\section{Results}

The demographic and clinical profiles of all the subjects (Ischemic stroke) and control did not differ significantly with regard to age $(58.62 \pm 11.7$ vs. $57.15 \pm 12.26, \mathrm{P}=0.391)$ and sex as shown in (Tables 1 \& 2) shows the significant increased level of Neuron-Specific Enolase (NSE) and serum glucose in ischemic stroke patients, as compared with control (26.55 vs. $8.64 \mathrm{P}=0.001)$ and $(131.4 \pm 22.7$ vs $115.5 \pm 16.72, \mathrm{p}=0.002)$, respectively. Ischemic stroke patients also showed statistically significant increased levels of LDL (169.3 \pm 24.3 vs. $89.6 \pm 11.3, \mathrm{P}=0.007)$, TG (191.0 \pm 31.6 vs. $117.4 \pm 27.7, \mathrm{P}=0.004)$, and decreased level of HDL (30.7 \pm 6.5 vs. $45.3 \pm 11.1 \mathrm{P}=0.05$ ), respectively, as compared to the control. In the acute phase of brain infarction, the concentrations of NSE in the serum is significantly increased with an increase in the blood glucose levels, in the controls, Normoglycemic ischemic stroke patients, and Hyperglycemic ischemic stroke patients, respectively (Figure 1). (Tablse 3) demonstrates a comparison between Normoglycemic Ischemic stroke patients and Hyperglycemic ischemic stroke patients. Hyperglycemic ischemic stroke patients had increased levels of NSE (29.2 vs. $18.7, \mathrm{P}=0.05)$, LDL $(180.0 \pm 19.2$ vs. $152.8 \pm 21.3, \mathrm{P}$ $=0.05)$, $\mathrm{TG}(202.3 \pm 25.3$ vs. $170.9 \pm 26.7, \mathrm{P}=0.05)$, serum glucose (147.4 \pm 11.2 vs. $105.3 \pm 7.6 \mathrm{P}=0.003)$, and NIHSS score $(14.9 \pm 7.2$ vs. $9.9 \pm 5.7, \mathrm{P}=0.007)$, with a significant decreased level of HDL (29.4 \pm 6.2 vs. $33.9 \pm 5.4, \mathrm{P}=0.005)$, as compared to Normoglycemic ischemic stroke patients. Serum NSE level in Hyperglycemic stroke patients was also found to be positively correlated with the serum glucose level $(r=0.673 \mathrm{P}<0.01)$ shown in (Figure 2). 
Table 1: Demographic characteristics.

\begin{tabular}{|c|c|c|c|}
\hline Variables & $\begin{array}{c}\text { IS group } \\
(\mathbf{n = 4 9 )}\end{array}$ & $\begin{array}{c}\text { Control group } \\
\text { (n=50) }\end{array}$ & p-value \\
\hline Age & $58.62 \pm 11.7$ & $57.15 \pm 12.26$ & 0.391 \\
\hline Gender (male) & $30(61.2 \%)$ & $33(66 \%)$ & 0.514 \\
\hline Hypertension & $35(71.4 \%)$ & $15(30 \%)$ & 0.001 \\
\hline Smoking & $12(24.5 \%)$ & $13(26 \%)$ & 0.724 \\
\hline Diabetes mellitus & $14(28.6 \%)$ & $13(26 \%)$ & 0.495 \\
\hline Alcohol & $14(28.6 \%)$ & $13(26 \%)$ & 0.425 \\
\hline
\end{tabular}

Table 2: Comparison between control and ischemic stroke groups.

\begin{tabular}{|c|c|c|c|}
\hline Variables & $\begin{array}{c}\text { IS group } \\
\text { (n=49) }\end{array}$ & $\begin{array}{c}\text { Control group } \\
\text { (n=50) }\end{array}$ & p-value \\
\hline NSE (median, $\mathrm{ng} / \mathrm{ml})$ & 26.55 & 8.64 & 0.002 \\
\hline Serum glucose (mg/dl) & $131.4 \pm 22.7$ & $115.5 \pm 16.72$ & 0.006 \\
\hline HDL (mg/dl) & $30.7 \pm 6.5$ & $45.3 \pm 11.1$ & 0.05 \\
\hline LDL (mg/dl) & $169.3 \pm 24.3$ & $89.6 \pm 11.3$ & 0.007 \\
\hline TG (mg/dl) & $191.0 \pm 31.6$ & $117.4 \pm 27.7$ & 0.004 \\
\hline Alcohol & $14(28.6 \%)$ & $13(26 \%)$ & 0.425 \\
\hline
\end{tabular}

Table 3: Comparison between normal ischemic stroke patients and hyperglycemic stroke patients.

\begin{tabular}{|c|c|c|c|}
\hline \multirow{2}{*}{ Variables } & $\begin{array}{c}\text { Normoglycemic IS group } \\
(\mathbf{n = 1 9 )}\end{array}$ & $\begin{array}{c}\text { Hyperglycemic IS group } \\
\text { (n=30) }\end{array}$ & p-value \\
\hline NSE (median, $\mathrm{ng} / \mathrm{ml})$ & 18.7 & 29.2 & 0.05 \\
\hline Serum glucose (mg/dl) & $105.3 \pm 7.6$ & $147.4 \pm 11.2$ & 0.003 \\
\hline HDL (mg/dl) & $33.9 \pm 5.4$ & $29.4 \pm 6.2$ & 0.009 \\
\hline LDL (mg/dl) & $152.8 \pm 21.3$ & $180.0 \pm 19.2$ & 0.05 \\
\hline TG (mg/dl) & $170.9 \pm 26.7$ & $202.3 \pm 25.3$ & 0.05 \\
\hline HIHSS score & $9.9 \pm 5.7$ & $14.9 \pm 7.2$ & 0.007 \\
\hline
\end{tabular}

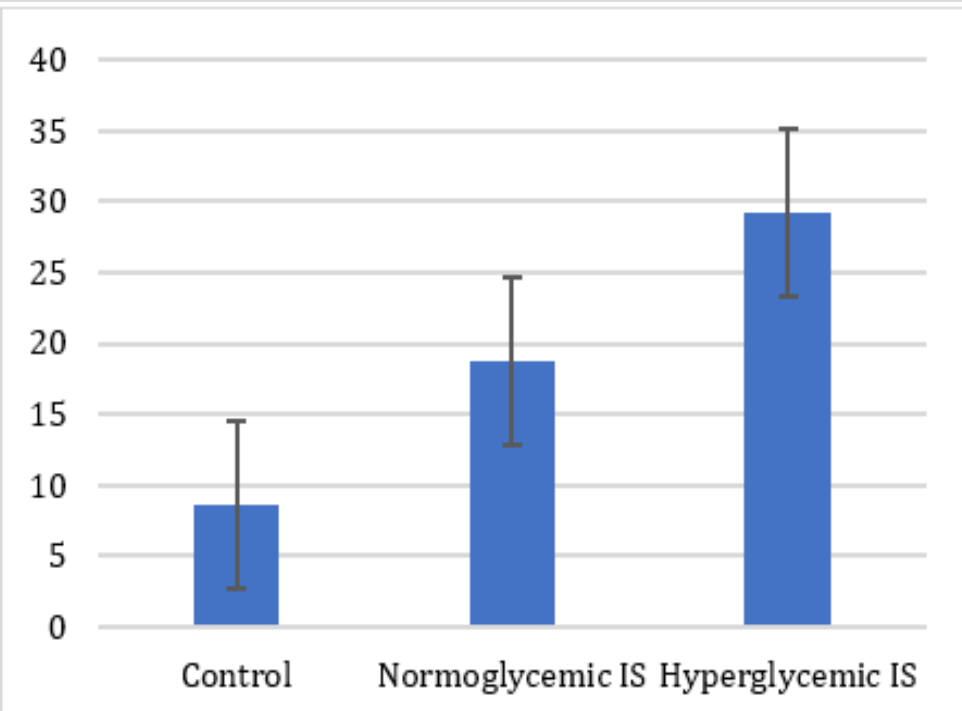

Figure 1: Level of serum neuron-specific enolase concentrations in control, Normoglycemic Ischemic stroke patients and Ischemic stroke patients with hyperglycemia. Hyperglycemia was defined as blood glucose concentration of $>7 \mathrm{~m}$ mol $/ 1$. 


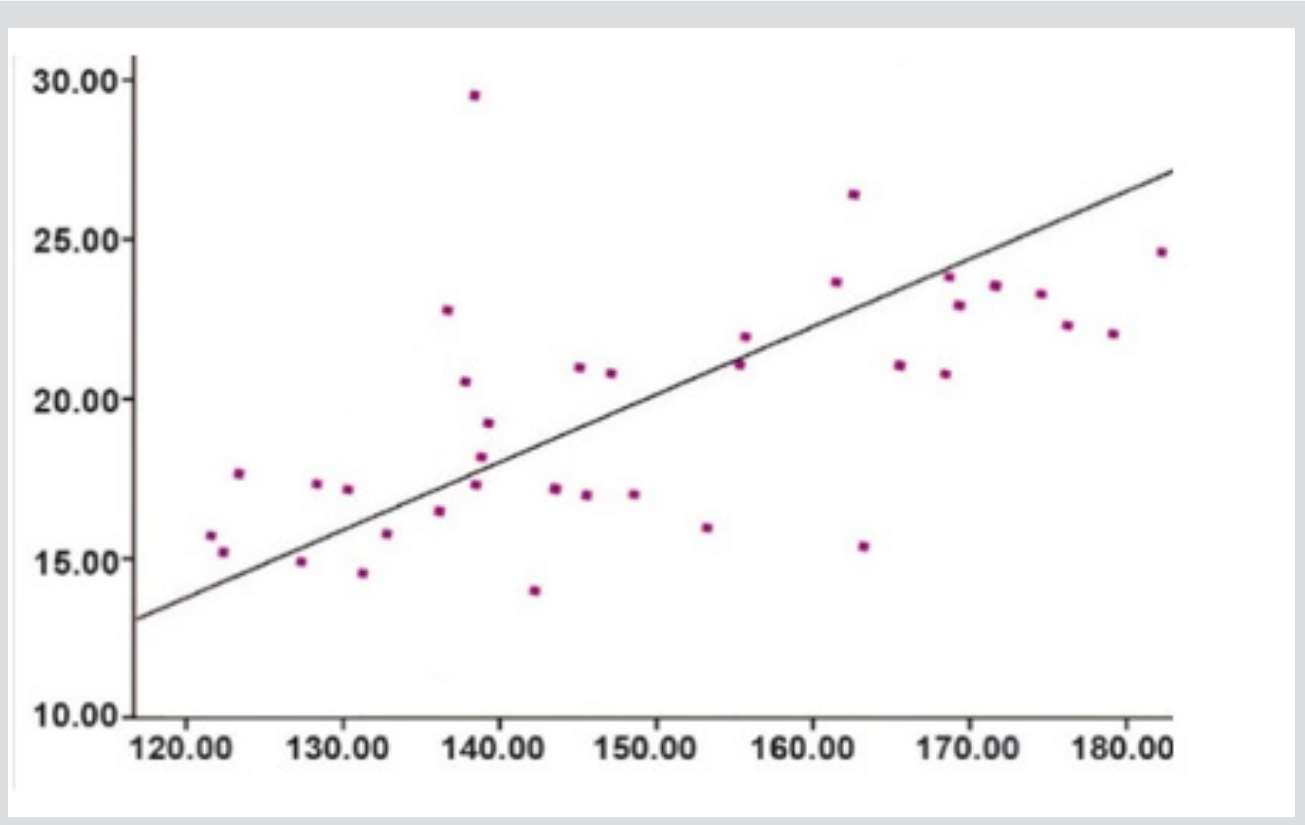

Figure 2: Correlation between Neuron-specific enolase concentration and serum glucose level.

\section{Discussion}

Neuron-specific enolase is a soluble protein enolase enzyme (2-phopho-D-glyceride hydrolase) of the glycolytic pathway, with a total molecular weight of approximately 80000 daltons [13]. It counts $1.5 \%$ of cell-soluble brain proteins and is found predominantly in neurons and neuroendocrine cells [14]. After various types of insults in the central nervous system, such as, cerebral infarction, hypoxia trauma, and seizure, the blood brain barrier gets disturbed, and substantial astroglial disintegration makes the NSE leak into the cerebrospinal fluid and serum [15]. It is mentioned as a possible reliable marker of neuronal tissue damage [16]. We evaluated the serum NSE level rather than the CSF level, because the daily serum sampling was practical and posed no risk for older patients.In the previous reports, the levels of NSE in the serum peaked within the first 96 hours of cerebral infarction, and in some cases as late as day six after infarction [7].

The half-life of NSE in the serum has been reported to be about 48 hours [17], hence, the serum levels of NSE will be expected to rise as long as damage due to the infarction continues and NSE is washing out of the brain tissue. The time to the peak serum level of NSE in our study was 72 hours after infarction, which compares well with the 48-hour half-life reported in the literature. Our data show highly significant increased admission NSE levels in stroke patients as compared to the control group. The increased NSE serum levels correspond to the ischemia-induced cytoplasm loss of NSE in the neurons and are detectable before irreversible neuronal damage takes place [17]. A conspicuous finding of the present study that the concentration of serum NSE levels in hyperglycemic stroke patients was significantly more than those in the normoglycemic stroke patient group, adds further support to the concept that hyperglycemia enhances neuronal necrosis, and hyperglycemiainduced lactic acidosis in the ischemic brain not only damages glial and endothelial cells, but may also exacerbate the biochemical events in the ischemic penumbra that lead to neuronal cell death and release of biochemical markers, shown by the positive correlation between NSE and the serum glucose level (Figure 2) during the acute stage of ischemic stroke. One study has shown that hyperglycemia in patients with pure motor stroke, due to lacunar infarctions, is not associated with increased NSE levels [18].

The problem of hyperglycemia in acute stroke is important, as it occurs in about $20 \%$ of non-diabetic patients [18]. The mechanism is not entirely clear, but one hypothesis is that it results from a neuroendocrine stress response [5,6]. Ischemic stroke is a heterogeneous pathophysiological entity with vastly different pathways, leading to indistinguishable clinical presentations. Well-recognized mechanisms of ischemic stroke include cardiac or artery-to-artery embolism, atherothrombosis of an extracranial carotid or intracranial artery, and nonatherosclerotic disease of small diameter penetrating arteries [19]. The lipid profile might have a more important role in those ischemic strokes that are the consequence of atherosclerosis of larger arteries [20]. In our study Low Density Lipoproteins (LDL) and Triglycerides (TG) increased with a significantly decreased level of High Density Lipoproteins (HDL), which is supported by several other studies [21]. Previous studies have shown that elevated LDL is a risk factor for vascular disease and high levels of HDL are protective [11,22]. One study has demonstrated that an association between post stroke lipids and prognosis may vary by sex. In women, lipids were not associated with the outcome; in men, a higher level of TG and LDL were associated with worse prognosis [23]. The mechanism 
of lipid changes remains unclear, but it is thought to relate in part to the stress and associated catecholamine overproduction of an acute stroke [24]. Baseline lipid panel components have not been associated with an increased stroke risk in one cohort study, hence, treatment with cholesterol-lowering medications and lipid measurements at several points may be better markers of stroke risk [25].

\section{Conclusion}

The serum level of NSE does seem to be higher in stroke patients than in controls, and it does appear to correlate with serum glucose level and NIHSS score. Hyperglycemia predicts an increased risk of poor outcome after ischemic stroke and it is reflected by a significantly increased level of Neuron-Specific Enolase.

\section{References}

1. Sacco RL, Kasner SE, Broderick JP, Caplan LR, Connors JJ, et al. (2013) An updated definition of stroke for the 21st century: a statement for healthcare professionals from the American Heart Association/ American Stroke Association. Stroke 44(7): 2064-2089.

2. Lopez AD, Mathers CD, Ezzati M, Jamison DT, Murray CJ (2006) Global and regional burden of disease and risk factors, 2001: systematic analysis of population health data. Lancet 367(9524): 1747-1757.

3. Scott JF, Robinson GM, French JM, O Connell JE, Alberti KG, et al. (1999) Prevalence of admission hyperglycaemia across clinical subtypes of acute stroke. Lancet 353(9150): 376-377.

4. Koistinaho J, Pasonen S, Yrjanheikki J, Chan PH (1999) Spreading depression-induced gene expression is regulated by plasma glucose. Stroke 30(1): 114-119.

5. Wass CT, Lanier WL (1996) Glucose modulation of ischemic brain injury: review and clinical recommendations. Mayo Clin Proc 71(8): 801-812.

6. Weir CJ, Murray GD, Dyker AG, Lees KR (1997) Is hyperglycaemia an independent predictor of poor outcome after acute stroke? Results of a long-term follow up study. BMJ 314(7090): 1303-1306.

7. Cunningham RT, Watt M, Winder J, McKinstry S, Lawson JT, et al. (1996) Serum neurone-specific enolase as an indicator of stroke volume. Eur ] Clin Invest 26(4): 298-303.

8. Missler U, Wiesmann M, Friedrich C, Kaps M (1997) S-100 protein and neuron-specific enolase concentrations in blood as indicators of infarction volume and prognosis in acute ischemic stroke. Stroke 28(10): 1956-1960.

9. Persson L, Hardemark HG, Gustafsson J, Rundstrom G, Mendel Hartvig I, et al. (1987) S-100 protein and neuron-specific enolase in cerebrospinal fluid and serum: markers of cell damage in human central nervous system. Stroke 18(5): 911-918.

10. Schaarschmidt H, Prange HW, Reiber H (1994) Neuron-specific enolase concentrations in blood as a prognostic parameter in cerebrovascular diseases. Stroke 25(3): 558-565.

\section{ISSN: 2574-1241}

DOI: 10.26717/BJSTR.2019.17.003064

Nguyen Huu Son. Biomed J Sci \& Tech Res

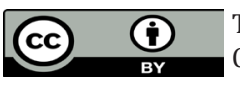

This work is licensed under Creative Commons Attribution 4.0 License

Submission Link: https://biomedres.us/submit-manuscript.php
11. Ballantyne CM, Herd JA, Ferlic LL, Dunn JK, Farmer JA, et al. (1999) Influence of low HDL on progression of coronary artery disease and response to fluvastatin therapy. Circulation 99(6): 736-743.

12. Miller GJ, Miller NE (1975) Plasma-high-density-lipoprotein concentration and development of ischaemic heart-disease. Lancet 1(7897): 16-19.

13. Marangos PJ, Schmechel D, Parma AM, Clark RL, Goodwin FK (1979) Measurement of neuron-specific (NSE) and non-neuronal (NNE) isoenzymes of enolase in rat, monkey and human nervous tissue. J Neurochem 33(1): 319-329.

14. Kato K, Suzuki F, Umeda Y (1981) Highly sensitive immunoassays for three forms of rat brain enolase. J Neurochem 36(3): 793-797.

15. Hardemark HG, Ericsson N, Kotwica Z, Rundstrom G, Mendel Hartvig I, et al. (1989) S-100 protein and neuron-specific enolase in CSF after experimental traumatic or focal ischemic brain damage. J Neurosurg 71(5 Pt 1): 727-731.

16. Selakovic V, Raicevic R, Radenovic L (2005) The increase of neuronspecific enolase in cerebrospinal fluid and plasma as a marker of neuronal damage in patients with acute brain infarction. J Clin Neurosci 12(5): 542-547.

17. Wunderlich MT, Ebert AD, Kratz T, Goertler M, Jost S, et al. (1999) Early neurobehavioral outcome after stroke is related to release of neurobiochemical markers of brain damage. Stroke 30(6): 1190-1195.

18. Sulter G, Elting JW, De Keyser J (1998) Increased serum neuron specific enolase concentrations in patients with hyperglycemic cortical ischemic stroke. Neurosci Lett 253(1): 71-73.

19. Shahar E, Chambless LE, Rosamond WD, Boland LL, Ballantyne CM, et al. (2003) Plasma lipid profile and incident ischemic stroke: the Atherosclerosis Risk in Communities (ARIC) study. Stroke 34(3): 623631.

20. Johnson CJ, Kittner SJ, McCarter RJ, Sloan MA, Stern BJ, et al. (1995) Interrater reliability of an etiologic classification of ischemic stroke. Stroke 26(1): 46-51.

21. Papadakis JA, Mikhailidis DP, Winder AF (1998) Lipids and stroke: neglect of a useful preventive measure? Cardiovasc Res 40(2): 265-271.

22. Gordon DJ, Probstfield JL, Garrison RJ, Neaton JD, Castelli WP, et al. (1989) High-density lipoprotein cholesterol and cardiovascular disease. Four prospective American studies. Circulation 79(1): 8-15.

23. Cuadrado Godia E, Jimenez Conde J, Ois A, Rodriguez Campello A, Garcia Ramallo E, et al. (2009) Sex differences in the prognostic value of the lipid profile after the first ischemic stroke. J Neurol 256(6): 989-995.

24. Myers MG, Norris JW, Hachniski VC, Sole MJ (1981) Plasma norepinephrine in stroke. Stroke 12(2): 200-204.

25. Willey JZ, Xu Q, Boden Albala B, Paik MC, Moon YP, et al. (2009) Lipid profile components and risk of ischemic stroke: the Northern Manhattan Study (NOMAS). Arch Neurol 66(11): 1400-1406.

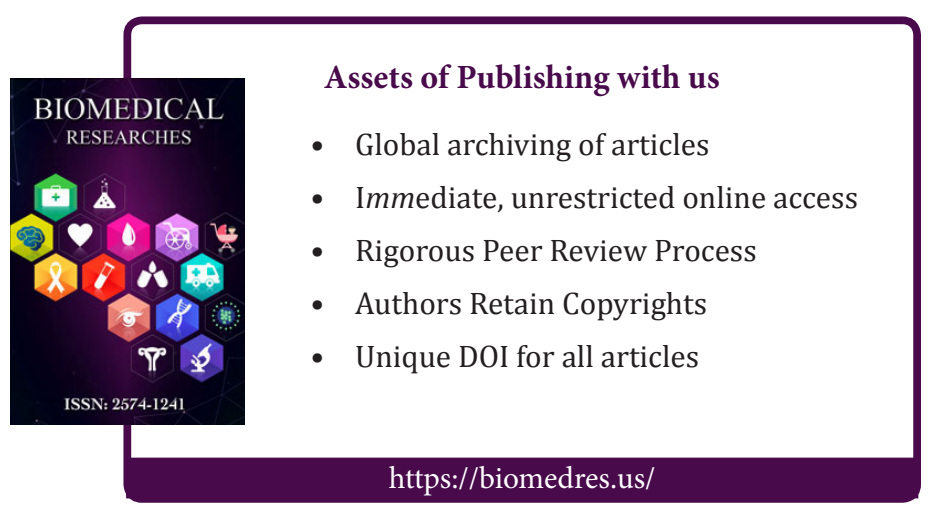

